\title{
A Bordetella pertussis fepA homologue required for utilization of exogenous ferric enterobactin
}

\author{
Bernard Beall and Gary N. Sanden \\ Author for correspondence: Bernard Beall. Tel: +1 404639 1237. Fax: +1 4046393123. \\ e-mail: beb0@ciddbd2.em.cdc.gov
}

Childhood and Respiratory Diseases Branch, National

Center for Infectious

Disease, Centers for

Disease Control and

Prevention, Mailstop $\mathrm{CO2}$

1600 Clifton Rd NE,

Atlanta, GA 30333, USA

\begin{abstract}
The bfeA (Bordetella ferric enterobactin) receptor gene was cloned from a Bordetella pertussis chromosomal library by using a screen in Escherichia coli to detect iron-repressed genes encoding exported proteins translationally fused to the $E$. coli phoA gene. The bfeA gene encoded a protein with a molecular mass of approximately $80 \mathrm{kDa}$ and about $50 \%$ amino acid sequence identity to both the fepA- and pfeA-encoded enterobactin receptors of $E$. coli and Pseudomonas aeruginosa, respectively. Enterobactin prepared from ironstarved E. coli cultures supported growth of B. pertussis and Bordetella bronchiseptica in the presence of the iron chelator ethylenediamine-di-(ohydroxyphenylacetic acid) (EDDA). Expression of the bfeA gene was induced by low iron availability, and iron-regulated expression appeared to be dependent upon the presence of the sequence contained within $\mathbf{3 7 0}$ bp upstream of the bfeA structural gene. An internal fragment of the bfeA structural gene and flanking regions were shown by Southern analysis to be highly conserved among Bordetella species. Insertional inactivation of bfeA in both B. pertussis and B. bronchiseptica greatly impaired their ability to grow in the presence of enterobactin and EDDA. These findings suggest that enterobactin produced by other respiratory flora could aid in the colonization of the respiratory tract by Bordetella species.
\end{abstract}

Keywords: Bordetella, enterobactin receptor, heterologous siderophore.

\section{INTRODUCTION}

Bacterial pathogens must obtain iron for growth, and for extracellular pathogens this requires the scavenging of iron from extracellular iron-binding glycoproteins in the host. This is often facilitated by the secretion of siderophores capable of binding ferric iron with high affinity. In many Gram-negative organisms, specific outer membrane receptors then bind iron-siderophore complexes which are internalized in a process requiring the integral cytoplasmic membrane protein TonB (Wang \& Newton, 1971; Hantke \& Braun, 1975; Braun \& Hantke, 1991).

Enterobactin, a cyclic triester of 2,3-dihydroxy- $N$ benzoyl-L-serine, is a siderophore produced upon iron

Abbreviations: AP, alkaline phosphatase; DP, 2,2-dipyridyl; EDDA, ethylenediamine-di-(o-hydroxyphenylacetic acid); SS-Fe, Stainer-Sholte lacking added iron; XP, 5-bromo-4-chloro-3-indolyl phosphate.

The GenBank accession number for the sequence reported in this paper is U13950. depletion by many members of the family Enterobacteriaceae, including Escherichia coli (O'Brien \& Gibson, 1970 ) and Salmonella typhimurium (Pollack \& Neilands, 1970). In E. coli transport of ferric-enterobactin across the inner and outer membranes requires several proteins, including TonB and the receptor FepA (Wayne \& Neilands, 1976). Recently the $p f e A$ gene of Pseudomonas aeruginosa, which encodes a ferric enterobactin receptor very similar structurally to FepA, was characterized and was found to be required for efficient utilization of exogenously supplied enterobactin (Dean \& Poole, 1993a). There is also strong evidence of a $f e p A$ homologue in Haemophilus species that allows the usage of ferric enterobactin as an iron source (Williams et al., 1990). The work presented here demonstrates $f e p A$-homologuedependent utilization of exogenous enterobactin by Bordetella species.

The genes encoding several other iron-regulated outer membrane receptors involved in iron uptake from various Gram-negative pathogens have been identified. For 
example, in $P$. aeruginosa, besides a ferric enterobactin receptor, outer membrane receptors for ferric pyoverdin (Meyer et al., 1990) and ferric pyochelin (Heinrichs et al., 1991) have been identified. In contrast, no siderophore receptors of Bordetella species have been identified, even though Bordetella species are known to acquire iron from transferrin and lactoferrin by a hydroxamate-siderophoredependent mechanism (Gorringe et al., 1990; Agiato \& Dyer, 1992; Armstrong \& Clements, 1993; Moore et al., 1995). In addition, Bordetella species apparently have at least one outer membrane protein that binds to transferrins directly (Redhead et al., 1987; Menozzi et al., 1991; Redhead \& Hill, 1991).

Iron transport systems in many Gram-negative bacterial species are repressed at high intracellular iron concentrations by the iron-binding repressor Fur (Calderwood \& Mekalanos, 1987; Braun et al., 1990; Stojiljkovic et al., 1994). As with the Fur proteins of several other Gramnegative bacteria, the Fur protein of Bordetella pertussis is functional in $E$. coli and apparently binds to a DNA sequence similar to that recognized by the $E$. coli Fur protein (Beall \& Sanden, 1995; Brickman \& Armstrong, 1995). On the basis of this observation we screened for $B$. pertussis genes encoding transported proteins which were iron-repressed in $E$. coli. Here we report the characterization of $b f e A$ (Bordetella ferric enterobactin receptor), which was cloned by this approach.

\section{METHODS}

Preparation of enterobactin. Enterobactin extracts were prepared from cultures of E. coli strain MT912 in $500 \mathrm{ml}$ ironstarved M9 minimal medium incubated for $12 \mathrm{~h}$ at $35^{\circ} \mathrm{C}$. Ethyl acetate extraction was used as previously described (Langman $\mathrm{et}$ al., 1972) with some modifications (Neilands, 1981). Culture supernatants were not acidified and enterobactin was not iron saturated during extraction. Ethyl acetate extracts were washed with $1 / 40$ th volume of $0 \cdot 1 \mathrm{M}$ sodium citrate buffer to remove charged species, and following evaporation of the ethyl acetate the residue was dissolved in methanol and stored at $-20^{\circ} \mathrm{C}$. These preparations were used either immediately or within 2 weeks of preparation. During this time there was no significant decrease in the growth enhancement conferred by these extracts upon the E. coli aroB strain $\mathrm{H} 1443$ in media containing 2,2dipyridyl (DP) (data not shown). The concentration of enterobactin was measured in ethyl acetate extracts from its absorbance at $316 \mathrm{~nm}$ as described by Langman et al. (1972).

Assays for enterobactin utilization. Growth of $B$. pertussis and $B$. bronchiseptica cultures was monitored in modified StainerSholte minimal medium (von Koenig et al., 1988) lacking added iron (SS-Fe) containing 20-45 $\mu \mathrm{g}$ EDDA $\mathrm{ml}^{-1}$ and $5 \mu \mathrm{M}$ enterobactin. To assess growth on solid medium $B$. pertussis stains were grown on Regan Lowe agar, washed in SS-Fe, and streaked onto SS-Fe agar containing 15-30 $\mu \mathrm{g} \mathrm{EDDA} \mathrm{ml}^{-1}$ and $5 \mu \mathrm{M}$ enterobactin. The presence or absence of growth was determined after $4-5 \mathrm{~d}$ incubation at $37^{\circ} \mathrm{C}$. Overnight Luria (L) broth cultures of $B$. bronchiseptica were diluted to an $\mathrm{OD}_{600}$ of $0 \cdot 3$ and $100 \mu \mathrm{l}$ was spread on L-agar plates containing $100 \mu \mathrm{g}$ EDDA $\mathrm{ml}^{-1}$ or SS-Fe agar plates lacking added iron and containing $45 \mu \mathrm{g}$ EDDA ml${ }^{-1}$. Disks were laid on the surface of the agar, to which $10 \mu$ threefold-concentrated overnight Lbroth culture of enterobactin-producing $E$. coli strains or $5 \mu \mathrm{l}$ of $50 \mu \mathrm{M}$ enterobactin was added. The diameters of growth zones around the disks were measured after $24 \mathrm{~h}$ at $35^{\circ} \mathrm{C}$. Culture from aroB mutant strains (strains $\mathrm{H} 5058, \mathrm{H} 1443$ or $\mathrm{H} 1876$; see Table 2) was added to the disks as negative controls.

Alkaline phosphatase (AP) assay. AP activities of B. pertussis, $B$. bronchiseptica and $E$. coli strains containing a translational $b f e A-p h o A$ fusion were measured as previously described (Brickman \& Beckwith, 1975).

Media, growth conditions and antibiotics. Regan Lowe agar (Regan \& Lowe, 1977) was used for the routine growth of $B$. pertussis strains. L-broth was used for growth of $E$. coli and $B$. broncbiseptica. L-broth or L-agar containing 50-450 $\mu \mathrm{g}$ EDDA $\mathrm{ml}^{-1}$ or 50-200 $\mu \mathrm{M}$ DP was used as iron-deficient medium for $E$. coli and $B$. bronchiseptica. SS-Fe supplemented with $0-45 \mu \mathrm{g}$ EDDA ml ${ }^{-1}$ was used as iron-limiting media for $B$. pertussis and B. bronchiseptica. SS-Fe containing $50 \mu \mathrm{M} \mathrm{FeCl}$ ( $\mathrm{SS}+\mathrm{Fe}$ ) was used for some experiments. Antibiotics were used at the following concentrations for the growth of $E$. coli, $B$. bronchiseptica and $B$. pertussis: kanamycin at $35 \mu \mathrm{g} \mathrm{ml}^{-1}$; ampicillin and nalidixic acid at $100 \mu \mathrm{g} \mathrm{ml}^{-1}$; gentamicin at $10 \mu \mathrm{g} \mathrm{ml}^{-1}$; tetracycline at $15 \mu \mathrm{g} \mathrm{ml}^{-1}$. Human holo-transferrin was obtained from Sigma and used in some experiments to supplement media at the concentration of $200 \mu \mathrm{g} \mathrm{ml}^{-1}$.

Transformation and conjugation. Plasmids were transformed into $E$. coli by standard methods. Chromosomal integration of plasmids into B. pertussis and B. bronchiseptica was facilitated by electroporation with a Bio-Rad Gene Pulser at a voltage of $2500 \mathrm{~V}$ and at a capacitance of $25 \mu \mathrm{F}$, producing time constants of $4.0-4.6 \mathrm{~ms}$. After electroporation of B. pertussis, cells were spread onto the surface of Regan Lowe agar and incubated at $37^{\circ} \mathrm{C}$ for $3 \mathrm{~h}$. At this time kanamycin was spread over the plates to a concentration of $35 \mu \mathrm{g} \mathrm{m} \mathrm{m}^{-1}$. Transformant colonies typically appeared after $4-6 \mathrm{~d}$ at $37^{\circ} \mathrm{C}$. Following electoporation of $B$. bronchiseptica, cells were incubated in L-broth for $2 \mathrm{~h}$ before plating on kanamycin L-agar. The integrational plasmids pVK11, pVK12, pGN11 and pGN12 were introduced into $B$. bronchiseptica and $B$. pertussis by conjugation with the donor strain SM10 as previously described for other pSS1129 derivatives (Stibitz, 1994). Transformants and conjugants were subjected to Southern analysis for verification of the expected chromosomal constructs. Chromosomal constructs were always maintained in Bordetella strains by the presence of kanamycin or gentamicin, which had no detectable influence on growth rate in any of the media used.

Plasmids and strains. Plasmids used for this work are described in Table 1. Plasmids pPHO1, pPHO2, and $\mathrm{pPHO} 3$ were a gift from Dr Terri Kenney (Emory University). These plasmids are pBR322 derivatives and contain several unique restriction sites preceding a promoterless $p h o A$ gene lacking its $5^{\prime}$ sequence including the first 11 codons encoding the mature AP. The plasmids differ from each other only by their translational reading frames relative to $p h o A$ in the multiple cloning site. The kanamycin resistance cassette from pDG102 (Driks et al., 1994) was inserted into the Bam HI sites of these plasmids to obtain pPH1, pPH2 and pPH3. Plasmid pSS1129 was a gift from Dr Scott Stibitz (Stibitz, 1994) and was used for construction of plasmids pVK11, pVK12, pGN11 and pGN12 used for integrational analysis of the $b f e A$ region in $B$. pertussis and $B$. broncbiseptica. The DNA fragments within integrational plasmids used for determining the functional boundaries of the bfe $A$ gene are shown in Fig. 7. Plasmid pPK5 is a pPH1 derivative, while $\mathrm{pKS} 3$ is a derivative of $\mathrm{pUK} 19$ which contains a kanamycin resistance gene selectable in a wide range of bacterial species (Driks et al., 1994). Plasmids $\mathrm{p} 415 \mathrm{~B} 1$ and p415B2, used for complementation of Bordetella bfe $A$ mutants, were derivatives of the broad-host-range replicative plasmid 
Table 1. Plasmids used in this study

\begin{tabular}{|c|c|c|}
\hline Plasmid & Relevant features & $\begin{array}{l}\text { Reference } \\
\text { or source }\end{array}$ \\
\hline $\mathrm{pPHO} 1,2,3$ & $\mathrm{pBR} 322$-derived $p h o A$ fusion vector, $\mathrm{Ap}^{\mathrm{r}}$ & T. Kenney \\
\hline pPH1, 2, 3 & pPHO1, 2, 3 with $\mathrm{Kan}^{\mathrm{r}}$ cassette & This work \\
\hline $\mathrm{pKP5}$ & $\begin{array}{l}\text { pPH1 derivative containing translational } \\
\text { bfe-pho } A \text { fusion preceded by } 1.5 \mathrm{~kb} \text { of } \\
\text { chromosomal sequence, } A p^{\mathrm{r}} \mathrm{Kan}^{\mathrm{r}}\end{array}$ & This work \\
\hline pKP3 & $\begin{array}{l}\text { pKP5 deletion derivative containing bfe-pbo } A \\
\text { preceded by } 370 \mathrm{bp} \text { of chromosomal sequence }\end{array}$ & This work \\
\hline pDG102 & $\mathrm{Kan}^{\mathrm{r}}$ cassette source & Driks et al. (1994) \\
\hline pUK19 & pUC19 with $\operatorname{Kan}^{r}$ cassette, $A p^{r} \operatorname{Kan}^{r}$ & Driks et al. (1994) \\
\hline $\mathrm{pKS3}$ & $\begin{array}{l}\text { pUK19 containing } 736 \text { bp structural gene } \\
\text { fragment of } b f_{e} A\end{array}$ & This work \\
\hline pKP1 & $\begin{array}{l}\text { pUC19 derivative containing the } b f e A \text { gene, } \\
1.5 \mathrm{~kb} \text { of upstream and } 400 \mathrm{bp} \text { of downstream } \\
\text { flanking sequence }\end{array}$ & This work \\
\hline pSS1129 & Broad-host-range integrational vector, $\mathrm{Gm}^{\mathrm{r}} \mathrm{Ap}{ }^{\mathrm{r}}$ & Stibitz (1994) \\
\hline $\mathrm{pVK} 11,12$ & $\begin{array}{l}\text { pSS1129 derivatives containing } 5^{\prime} \text { end of } b f e A \\
\text { and putative promoter region }\end{array}$ & This work \\
\hline pGN11, 12 & pSS1129 derivatives containing $3^{\prime}$ end of $b f e A$ & This work \\
\hline pRK415 & Broad-host-range replicative vector, Tet $^{r}$ & Keen et al. (1988) \\
\hline p415B1, 2 & $\begin{array}{l}\text { pRK415 derivatives containing } b f e A \text { and } \\
\text { putative promoter region }\end{array}$ & This work \\
\hline pCI & T7 expression vector & Promega \\
\hline $\mathrm{pCI} 7$ & $\begin{array}{l}\mathrm{pCI} \text { derivative containing } b f e A \text { under control of } \\
\text { the } \mathrm{T} 7 \text { promoter }\end{array}$ & This work \\
\hline
\end{tabular}

pRK415 (Keen et al., 1988). Plasmid pCI7, which is a derivative of pCI (Promega), contains the $b f e A$ structural gene on a $2.3 \mathrm{~kb}$ $X m n I-N c o I$ fragment under the control of the phage $\mathrm{T} 7$ promoter.

The strains used for this study are described in Table 2. E. coli strain KS330 contains the $\operatorname{degP4}$ allele, which decreases degradation of various periplasmic fusion proteins (Strauch \& Beckwith, 1988; Strauch et al., 1989). KS330 also contains the lpp-5508 mutation, which results in a leaky outer membrane through which periplasmic protein or outer membrane protein fusions to E. coli AP can diffuse (Strauch \& Beckwith, 1988; Giladi et al., 1993). On agar plates containing XP (5-bromo-4chloro-3-indolyl phosphate), fusions of outer membrane proteins to AP in strain KS330 often result in a blue halo on the agar, while enzymic activity of AP fusions to periplasmic domains of inner membrane proteins remains cell-associated (Strauch \& Beckwith, 1988; Giladi et al., 1993).

Cloning the bfeA promoter region and structural gene. Random $B$. pertussis chromosomal fusions to pho $A$ were made by digesting chromosomal DNA to completion by any one of a number of restriction enzymes, and ligating the digests with a mixture of phosphatase-treated $\mathrm{PPH} 1, \mathrm{pPH} 2$ and $\mathrm{pPH} 3$ that had been digested with a restriction enzyme producing compatible ends to the chromosomal fragments. For the work described here, only the ligation of StuI-digested chromosomal DNA into a mixture of EcoRV-cleaved $\mathrm{pPH} 1, \mathrm{pPH} 2$ and $\mathrm{pPH} 3$ is described. This ligation mixture was transformed into strain KS330 and plated on L-agar containing ampicillin, $150 \mu \mathrm{g}$ XP $\mathrm{ml}^{-1}$, and $200 \mu \mathrm{M}$ DP. Individual blue colonies were streaked in duplicate onto L-agar containing both XP and DP, and onto Lagar containing $\mathrm{XP}$ and $20 \mu \mathrm{M}$ added $\mathrm{FeCl}_{3}$. Colonies exhibiting more activity with iron-deficient conditions were stored for future analysis. Plasmid minipreps were prepared for sequence analysis as described by Bron (1990) from colonies exhibiting both blue haloes and increased AP activity upon iron limitation. The plasmid that was analysed for this work contained a $2.5 \mathrm{~kb}$ StuI fragment cloned in the EcoRV site of pPH3 and was designated $\mathrm{PPK} 5$. A derivative of $\mathrm{pPK} 5$ was made by deletion of an EcoRV fragment, resulting in the removal of all but $373 \mathrm{bp}$ of chromosomal sequence upstream of $b f e A$. This chromosomal fragment encompassing the chromosomal region from the EcoRV to the StuI site within $b f e A$, together with the vector kanamycin resistance determinant, was subcloned in both orientations as an EcoRI fragment into the conjugative vector pSS1129. These plasmids were designated pVK11 and pVK12.

To clone the entire $b f e A$ gene and additional downstream DNA, the integrational plasmid $\mathrm{pPK} 5$ was used to transform $B$. pertussis strain 82 to kanamycin resistance, and the chromosomal DNA was then digested with $K p n$ I. The DNA was ligated with KpnI-digested pUC19 and used to transform E. coli LE392 to kanamycin resistance, resulting in plasmid $\mathrm{pKP1}$.

DNA sequencing. Appropriate M13mp18 and M13mp19 (Messing, 1983) subclones were sequenced according to the Sequenase protocol (US Biochemical Corp.) using the universal primer and various oligonucleotides corresponding to the $b f e A$ region. pPK5 DNA was sequenced according to the Sequenase protocol for double-stranded DNA with a primer to the $5^{\prime}$ end of the $p b o A$ gene. Both strands of the $b f e A$ region were sequenced to obtain the data in Fig. 2.

Southern analysis. This was performed using Bordetella chromosomal DNA prepared as previously described (Beall \& Sanden, 1995) with the Genius Kit (Boehringer Mannheim). A 736 bp 
Table 2. Bacterial strains

\begin{tabular}{|c|c|c|}
\hline Strain & Genotype & $\begin{array}{c}\text { Source } \\
\text { or reference }\end{array}$ \\
\hline \multicolumn{3}{|l|}{ E. coli } \\
\hline KS330 & lpp-5508 $\operatorname{deg} P 4 \Delta p h o A$ & $\begin{array}{l}\text { Strauch \& } \\
\text { Beckwith (1988) }\end{array}$ \\
\hline JM101 & $\begin{array}{r}\Delta(\text { lac-pro } A B) \mathrm{F}^{\prime}(\operatorname{tra} D 36 \\
\left.\text { pro } A B \text { lacI } I^{q} \text { lac } Z \Delta \mathrm{M} 15\right)\end{array}$ & Messing (1983) \\
\hline LE392 & $\begin{array}{l}\text { bsdR } 514\left(\mathrm{r}_{\mathrm{K}}^{-} \mathrm{m}_{\mathrm{K}}^{+}\right) \sup E 44 \\
\operatorname{supF} 58 \text { lac } Y 1 \text { or } \Delta(\operatorname{lacIZY}) \\
6 \text { galK2 galT22 melB1 } \\
\operatorname{trpR} 55\end{array}$ & Laboratory stock \\
\hline SM10 & $\begin{array}{l}\text { RP4-2 Tc::Mu, conjugation } \\
\text { strain }\end{array}$ & Stibitz (1994) \\
\hline MT912 & $\begin{array}{l}\text { thi trpT purE proC leuB lacY } \\
\text { mtl xyl rpsL azi fbu } A \text { tsx } \\
\sup A \text { fep } A \mathrm{Kan}^{\mathrm{r}}\end{array}$ & M. McIntosh \\
\hline MC4100 & $\begin{array}{l}\operatorname{araD139} \Delta(\operatorname{argF}-l a c) U 169 \\
r p s L 150 \text { relA1 flbB5301 } \\
\text { deoC1 ptsF25 rbsR }\end{array}$ & K. Hantke \\
\hline $\mathrm{H} 5058$ & $t s \times$ aroB cir fiu fep $A$ & K. Hantke \\
\hline H1443 & as $\mathrm{MC} 4100$ but aroB & K. Hantke \\
\hline H1876 & $\begin{array}{l}\text { as } \mathrm{H} 1443 \text { but } f i u:: \mathrm{Mud} 1 \mathrm{X} \\
\text { cir fep } A:: \operatorname{Tn} 10\end{array}$ & K. Hantke \\
\hline H306 & $\operatorname{ton} B$ & K. Hantke \\
\hline BL21(גDE3) & $\mathrm{F}^{\prime} o m p T \mathrm{r}_{\mathbf{B}} \mathrm{m}^{-} \mathrm{r}_{\mathbf{B}}^{-}$ & $\begin{array}{l}\text { Tabor \& } \\
\text { Richardson } \\
(1985)\end{array}$ \\
\hline \multicolumn{3}{|l|}{ B. pertussis } \\
\hline 82 & $\begin{array}{l}\text { Wild-type } \mathrm{Nal}^{\mathrm{R}} \text { clinical } \\
\text { isolate }\end{array}$ & $\begin{array}{l}\text { Laboratory } \\
\text { collection }\end{array}$ \\
\hline 83 & $82 \Omega p P K 5$ & This work \\
\hline 84 & $82 \Omega \mathrm{pKS} 3$ & This work \\
\hline 85 & $82 \Omega p G N 11$ & This work \\
\hline 86 & $82 \Omega p V K 11$ & This work \\
\hline \multicolumn{3}{|c|}{ B. bronchiseptica } \\
\hline 19385 & $\begin{array}{l}\text { ATCC } 19385 \mathrm{Nal}^{\mathbf{R}} \text { (wild- } \\
\text { type) }\end{array}$ & $\begin{array}{l}\text { Laboratory } \\
\text { collection }\end{array}$ \\
\hline 19386 & $19385 \Omega$ pPK5 & This work \\
\hline 19387 & $19385 \Omega \mathrm{pKS} 3$ & This work \\
\hline 19388 & 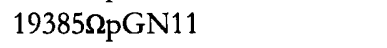 & This work \\
\hline 19389 & $19385 \Omega \mathrm{pVK} 11$ & This work \\
\hline \multicolumn{3}{|c|}{ B. parapertussis } \\
\hline A168 & Wild-type clinical isolate & $\begin{array}{c}\text { Laboratory } \\
\text { collection }\end{array}$ \\
\hline B. avium & Wild-type & $\begin{array}{c}\text { Laboratory } \\
\text { collection }\end{array}$ \\
\hline
\end{tabular}

* The symbol $\Omega$ indicates the strain contains a single homologously inserted copy of the indicated plasmid.

SalI-StuI bfe $A$ structural gene fragment was labelled and used as a probe as described by the manufacturers.

Outer membrane preparations. Protein extracts enriched in outer membrane proteins were prepared by Triton X-100 extraction as described by Schneider \& Parker (1982). $\left[{ }^{35} \mathrm{~S}\right]$ Methionine labelling of plasmid-encoded proteins. The labelling procedure has been described previously (Tabor \& Richardson, 1985). The DNA fragment cloned into pCI7 immediately downstream of the $\mathrm{T} 7$ promoter as well as the promoter-distal vector sequence was transcribed by phage T7 RNA polymerase encoded on phage $\lambda \mathrm{DE} 3$. On phage $\lambda \mathrm{DE} 3$, expression of T7 RNA polymerase was induced by the addition of $0.5 \mathrm{mM}$ IPTG since it is under control of the lac promoter. Precursors of transported proteins were enriched by the addition of $5 \mathrm{mM}$ sodium azide before labelling (Fortin et al., 1990; Oliver et al., 1990). Protein extracts were subjected to SDSPAGE and autoradiography.

\section{RESULTS}

\section{Cloning bfeA}

To identify iron-regulated genes from B. pertussis encoding exported proteins we screened for ironrepressed AP activity in E. coli KS330 transformed with plasmid-borne libraries of random $B$. pertussis DNA fragments fused to a truncated $p h o A$ gene. Plasmids from these transformants were likely to contain promoter regions normally regulated by the $B$. pertussis Fur protein, since the Fur proteins of $B$. pertussis and $E$. coli appear to be functionally interchangeable to a significant degree (Beall \& Sanden, 1995; Brickman \& Armstrong, 1995). Since the missing sequence in the truncated pho $A$ carries the signal sequence and first 11 codons encoding the mature enzyme, the AP activity of resulting translational fusions depends upon a chromosomal-fragment-encoded membrane export sequence that situates the PhoA portion of the fusion extracytoplasmically (Manoil \& Beckwith, 1985). Five of 400 transformants with AP activity resulting from transformation with a $S t u$ I fragment-pho $A$ library showed enhanced activity in the presence of DP. Two of these showed blue haloes on XP agar containing DP and were subjected to further analysis. These transformants contained identical plasmids, designated pPK5, with the truncated $p h o A$ gene fused to the $5^{\prime}$ portion of a gene designated $b f e A$ (Fig. 1a). The characterization of $b f e A$ is described below.

The $b f e A-p h o A$ fusion that was isolated in pPK5 contained a $2.5 \mathrm{~kb} S t u \mathrm{I}$ chromosomal fragment from $B$. pertussis with a 352 codon open reading frame which was fused in-frame to the truncated $p b o A$ at the EcoRV site of pPH1 (Fig. 1a). pPK5 was used to transform $B$. pertussis strain 82 to kanamycin resistance, which resulted in the Campbell-type insertion of the entire plasmid into the chromosome (Fig. 1a, b). DNA from one transformant was cleaved with $K p n I$, ligated with $K p n I$-digested pUC19 and subsequently used to transform E. coli LE392 to kanamycin resistance (Fig. 1c). The plasmid contained in these transformants, designated pKP1, contained the rest of the $b f e A$ gene and about 400 bp of additional downstream sequence (Fig. 1c).

\section{Nucleotide sequence of the $b f e A$ gene}

The DNA sequence of appropriate restriction fragments from $\mathrm{pKP} 1$ and $\mathrm{pPK} 5$ revealed an open reading frame preceded by a potential ribosome-binding site (Fig. 2, 


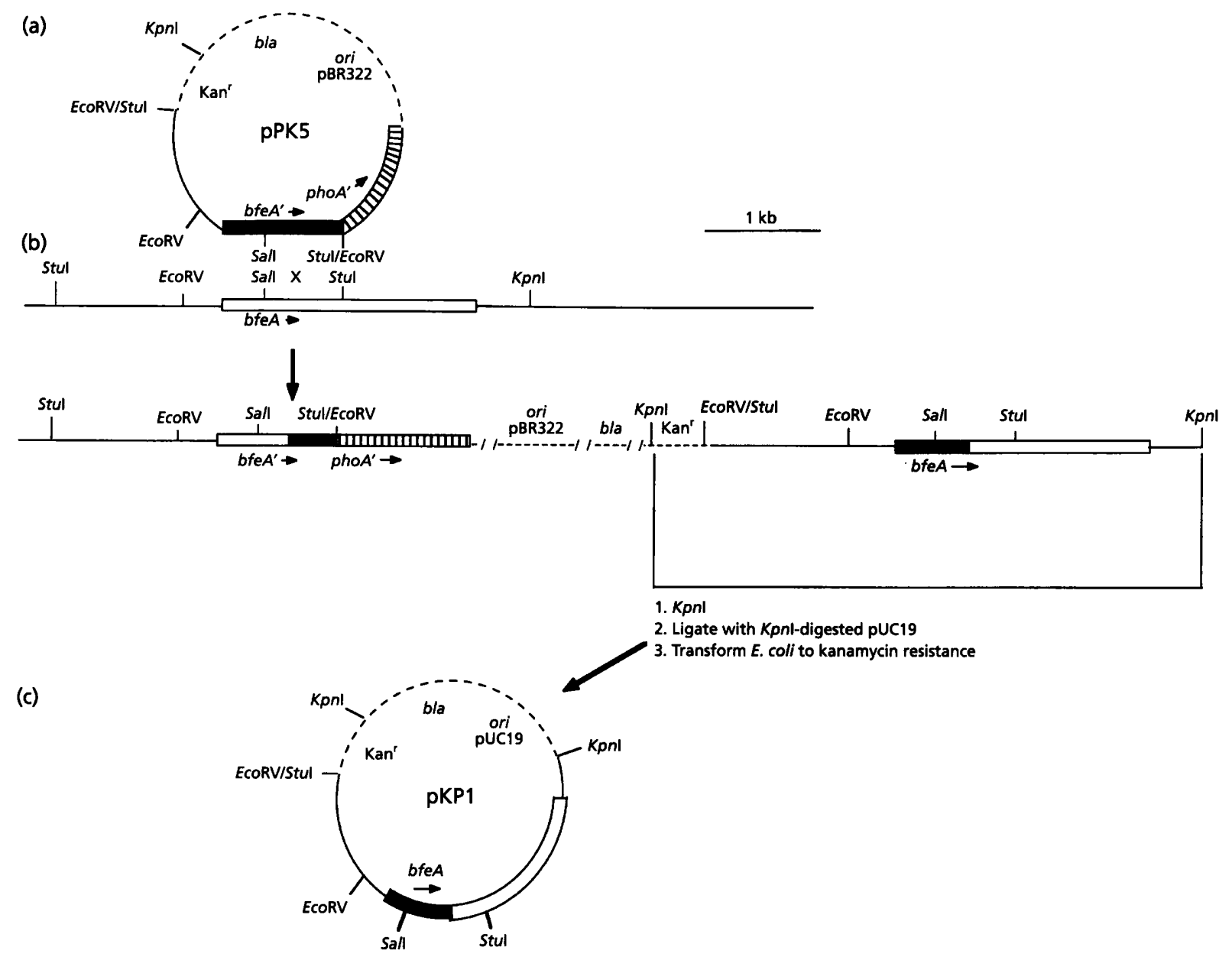

Fig. 1. Construction of B. pertussis and B. bronchiseptica strains with a chromosomal bfeA-phoA fusion and cloning of the entire bfeA gene. Dashed lines indicate vector sequence; solid lines indicate $B$. pertussis chromosomal DNA. (a) Plasmid pPK5 containing a translational bfeA-phoA fusion was (b) transformed into B. pertussis and B. bronchiseptica, resulting in homologous integration into the chromosome. (c) Chromosomal DNA from a B. pertussis strain containing the integrated PPK5 was cleaved with Kpnl, ligated into pUC19, and used to transform E. coli to kanamycin resistance, resulting in PKP1, which contains the entire bfeA gene.

positions 398-401); the open reading frame extends 352 codons to the junction of the $p h o A$ fusion at a StuI site (Fig. 2, position 1450). The sequence obtained with subclones of pKP1, which overlapped and extended downstream of the StuI library junction site, extended this open reading frame to 735 codons.

A database (GenBank) search revealed roughly $50 \%$ identity of the deduced $b f e A$ product with the $f e p A$ and $p f e A$ gene products of $E$. coli and $P$. aeruginosa respectively (Fig. 3). A putative signal peptide of 25 residues was predicted for $\mathrm{BfeA}$, with a cleavage site after the sequence AMA (Fig. 3), which is in agreement with the motif recognized by signal peptidase I (Perlman \& Halvorson, 1983). The amino acid sequences of BfeA, FepA and $\mathrm{PfeA}$, as with many other outer membrane proteins, contain hydrophobic residues at positions $3,5,7$ and 9 from the C-terminal phenylalanine and also share a conserved arginine residue at position 11 from the $\mathrm{C}$ terminus (Struyve et al., 1991) (Fig. 3). The region corresponding to the TonB box of E. coli (residues 34-40 of FepA; boxed in Fig. 3) (Lundrigan \& Kadner, 1986) does not appear to be particularly well conserved between $\mathrm{BfeA}$ and FepA. Two other regions in BfeA corresponding to TonB-dependent receptors (695-704 and $142-170$ of FepA) are very similar to FepA and identical to both FepA and PfeA at residues highly conserved in TonB-dependent receptors (specific residues not shown; Baumler et al., 1992) (Fig.3). Significantly, two regions corresponding to ligand-binding sites of FepA (residues also boxed in Fig. 3) (Murphy et al., 1990) are well conserved between the three proteins.

Based on the deduced similarity of BfeA to the FepA and $\mathrm{PfeA}$ proteins, and the blue halo results obtained in E. coli $\mathrm{KS} 330$ (pPK5) it is likely that the BfeA-PhoA hybrid protein encoded by pPK 5 is an outer membrane protein. This protein presumably contains 327 mature $\mathrm{BfeA}$ residues, with the fusion junction corresponding to residue 342 of FepA (Fig. 3). This residue lies within a 49residue region of FepA that is well conserved with $\mathrm{BfeA}$ and contains a surface-exposed epitope previously impli- 
1 AGTTCGGCGCGCACGGCGGCGCCCTGCAGATCGCGGATATCGACCCGGTGCGCCACCACGCCGGGCGCCACCTCGCTGGTATCAAACACGCCCTGGAAAA 101 CCGGCCGCTCCTTGCCGGGCACCGACAGGTAGTAGCGCGCGGCCTGTGGCGCGACAGATCGATCAGCGTCTGGCCCGCCACCAGGGCGGCGCCGGCGCC 201 GCCGCGCGGTGCGCGTGGAGGAGTCTGGGTCATGAATGAATGGCOATAOTGCAMAGCTPATGGCGCGTGCCGAAACCTTTGCCGGGATCTTCTCTAMCA

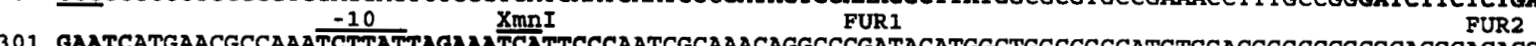
301 GAMTCATGAACGCCAAATCTTATTAGMATCATTCCCAATCGCAAACAGGCCCGATACATGGCTGGCCGCCATGTGGACGGGCCCGCGCACGCACACGGA FUR3 3 NCOI 401 GAAGCCGCATGTCCACCCCCCGATTCGCGCTGCATTACGCCAGCGCGTCAGTCCTGCTGGCCGCATCCGGCCTGGCCATGGCGCAGACGGCCACCCAGAT

$\begin{array}{llllllllllllllllllllllllllllllllll}M & S & T & P & R & F & A & \text { L } & \text { H } & \text { Y } & \text { A } & S & \text { A } & S & \text { V } & \text { L } & \text { L } & \text { A } & \text { A } & \text { S } & G & \text { L } & \text { A } & M & \text { A } & Q & \text { T } & \text { A } & \text { T } & Q & \text { I }\end{array}$

501 CCACGATCCGTCGCAGGTGCAGCAGATGGCGACGGTGCAGGTGCTGGGCACGGCCGAAGAGGAAATCAAGGAGTCGCTGGGCGTCTCGGTCATCACCGCC

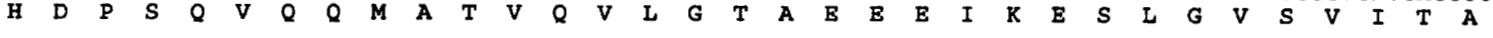

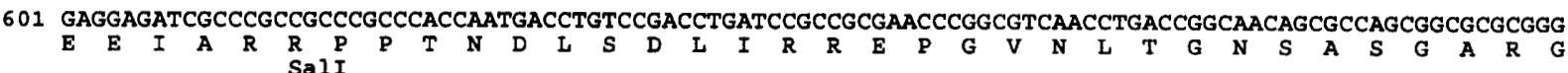
701 GCAACAGCCGCCAGGTCGACATCCGCGGCATGGGCCCCGAGAACACCCTCATCCTGATCGACGGCAAGCCCGTCACCTCGCGCAATGCGGTGCGCTATGG

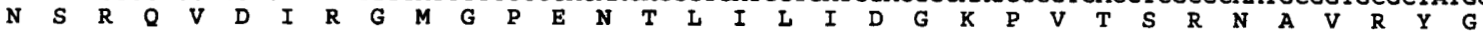

801 CTGGAACGGCGACCGGGACACGCGCGGGGACACCAACTGGGTGCCCGCGAGGAAGTCGAGCGCATCGAAGTGATCCGCGGCCCGGCCGCCGCCCGCTAC $\begin{array}{llllllllllllllllllllllllllllllllll}\text { W } & N & G & D & R & D & T & R & G & D & T & N & W & V & P & A & E & E & V & E & R & I & E & V & I & R & G & P & A & A & A & R & Y\end{array}$ 901 GCTTCOI 1001 GCCGCGAGGGCAACACCAACCGCGTCAATGCGCGCATCAGCGCGCCGATCAGCGACACGCTGAGCATGCGGCTGTACGGCAACTACAACAAGACCAATCC

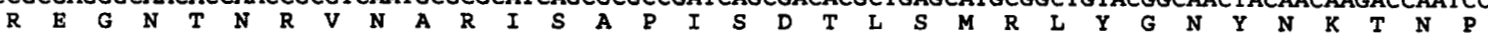

1101 GGATGCCCGCGACATCAACGCCGCCACGCGAACACCAGCGACAACGGCAACCCCTCGACCGCCGGACGCGAGGGCGTCATCAACCAGGACCTGAGCGCG $\begin{array}{llllllllllllllllllllllllllllllllllll}D & A & R & D & I & N & A & G & H & A & N & T & S & D & N & G & N & \text { P } & S & T & A & G & R & E & G & V & I & N & Q & D & L & S & A\end{array}$

1201 CTGTTCTCGTGGAAAGCCGACAGCCACAACACCGTGGACCTGGACATGGGCTTCAGCCGGCAGGGCAACCTGTTCGCCGGCGACACCATGAACAACGCCA

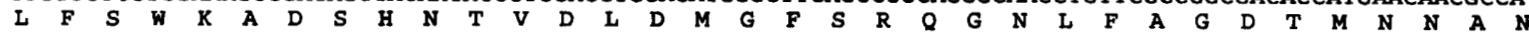

1301 ACAGCGACTTCTCGGACAGCCTGTACGGCAAGGAAACCAATGCGATGTACCGCGAGAACTATGCGCTGACGCACCGCGGCGTATACGACTGGGGCACCTC $\begin{array}{llllllllllllllllllllllllllllllllllll}S & D & F & S & D & S & \text { L } & \text { Y } & G & \text { K } & \text { E } & \text { T } & \text { N } & \text { A } & M & \text { Y } & \text { R } & \text { E } & \text { N } & \text { Y } & \text { A } & \text { L } & \text { T } & \text { H } & \text { R } & G & \text { V } & \text { Y } & \text { D } & \text { W } & G & T & S\end{array}$ 1401 GCGCGCCAGCGTCGGCTATGACTACACGCGCAACGCGCGCCAGCGCGAAGGCTTGGCCGGCGGCCCCGAGGGCGCGCCCACCGCGGGCGGCTACGACACC $\begin{array}{lllllllllllllllllllllllllllllllll}R & A & S & V & G & Y & D & Y & T & R & \mathbf{N} & A & R & \mathbf{Q} & \mathbf{R} & \mathbf{E} & \mathbf{G} & \mathbf{L} & \mathbf{A} & \mathbf{G} & \mathbf{G} & \mathbf{P} & \mathbf{E} & \mathbf{G} & \mathbf{A} & \mathbf{P} & \mathbf{T} & \mathbf{A} & \mathbf{G} & \mathbf{G} & \mathbf{Y} & \mathbf{D} & \mathbf{T}\end{array}$

1501 GCGCGCCTGAAGAACTGGCGCGCCGCGGCCGAGGCCAGCGTGCCGTTCCATCTCGGTTTCGAGCAGGTCGCCACGGTCGGCGTGGAATGGCTGCGCGAAT

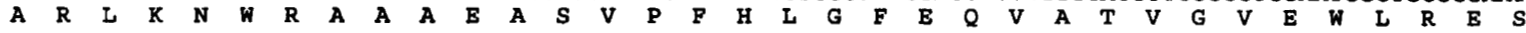

1601 CGCTGGAAGACCCCGCCGGCACGCGCCAGACCTATACCGGCGGCGCCATCGGCGGCACGGCCCCGGCCGACCGCGACCCGAAATCGCGCCAGACCAGCTA

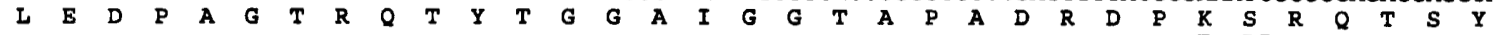

1701 TGCGCTGTTCGCCGAGGACAACATCGAGATCGACGAGCGCACCATGCTCACGCCCGGCGTGCGCCTGGACCACAACAGCG

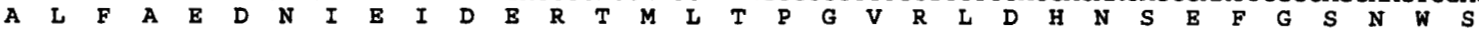

1801 CCCAGCCTGAACGCCTCGTACGCCGTCACCGACGCGCTCAAGGTGGCATCGCGCGCGCCTACAAGGCGCCCAACCTCTACCAATCCAACCCCAACTACC

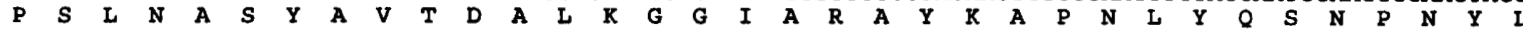
1901 TGCTGTACAGCCGCGGCAATGGCTGCCTGGCTCGCAGACCAACACCAACGGCTGCTATCTGGTCGGCAACGAGGACCTCTCGCCGGAAACCAGCGTCAA
L 2001 CAAGGAAATCGGCTTCGAGTACGACCCGGGCACGTGGCGCACCAGCATGGCCTATTTCCGCAACGACTACCGCAACAAGATCGTCGCCGGCACCGACGTC $\begin{array}{lllllllllllllllllllllllllllllllllll}\mathbf{K} & \mathbf{E} & \boldsymbol{I} & \mathbf{G} & \mathbf{F} & \mathbf{E} & \mathbf{Y} & \mathbf{D} & \mathbf{P} & \mathbf{G} & \mathbf{T} & \mathbf{W} & \mathbf{R} & \mathbf{T} & \mathbf{S} & \mathbf{M} & \mathbf{A} & \mathbf{Y} & \mathbf{F} & \mathbf{R} & \mathbf{N} & \mathbf{D} & \mathbf{Y} & \mathbf{R} & \mathbf{N} & \mathrm{K} & \mathbf{I} & \mathbf{V} & \mathbf{A} & \mathbf{G} & \mathbf{T} & \mathbf{D} & \mathbf{V}\end{array}$

2101 CAGTACCGCCTGGCCAATGGCGCCCGGGTGCTGCAATGGACCAACAGCGGCAAGGCCGTGGTCGAAGGGCTGGAAGGCAACCTGTTCATTCCGCTGGCCA

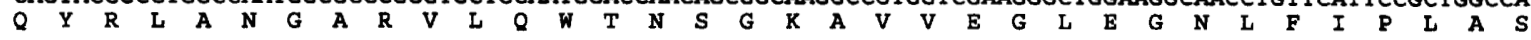

2201 GCAATCTCGACTGGAACACCAACTTCACCTACATGATCCAGTCCAAGGAAAAGGCACCGGCGAACCCTTGAGCGTGATTCCCGAATACACCATCAACAG

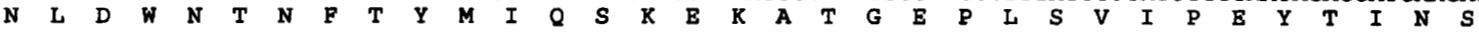

2301 CACGCTGGACTGGTTCTACACGCCGCAGCTGTCGTTCCAGGCAATCTCACCTATTACGGCAAGCAGGAAGGCCCGTCCACCAATGTACGCACCGGCGTC

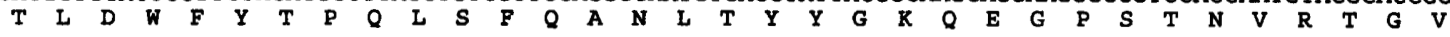

2401 GAACTGAACGGCGACGGCCGCCAGACCATCAGTCCGTATGCCCTGGCGGGCCTGAGCATGGGCTACGAAGTCAACCGGACCTGAAGTCCGCGTCGGCG

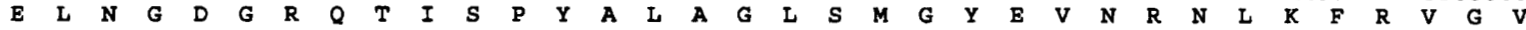

2501 TGAGCAACCTGTTCGACAAGCAGCTGTACCGCGAAGGCAATGCCAGCAGCGCGGGCGGGCCACCTACAACGAACCGGGGCGCGCCTATTACGCCACGGC

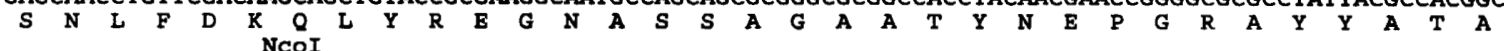
2601 GACGGTGTCGTTCTGACCATGGCGACGGCTCTCCTGCCGCGTCGCGCCGCCCCCTGGCTGCTGGCCGCCGCCCTGCGGCCGGCCGCATCGCGGGCCCAGC 2701 CGGCGGCCGTGCCGAGCGAACCGCCCGAGCGCGCGCGGGCCGCCTGGGCGTGCTGGGGCTGGTCCAGCAGACCGTGCTGGCGCGCGGCGGGGCTTGCGC 2801 AACGTGCGCCTCACCGTGGCCGTGCCGGCGGG

Fig. 2. Nucleotide sequence of the $b f e A$ gene and the predicted amino acid sequence of the BfeA protein. The Stul site at position 1452 was the site of the bfeA fusion to phoA. An inverted repeat possibly functioning in transcription termination is underlined (positions 176-203). A potential ribosome-binding site is indicated at positions 398-401. Potential -35 and -10 hexamers are overlined. Three 19-base sequences with homology to the consensus iron box recognized by the $E$. coli Fur protein are in bold. 


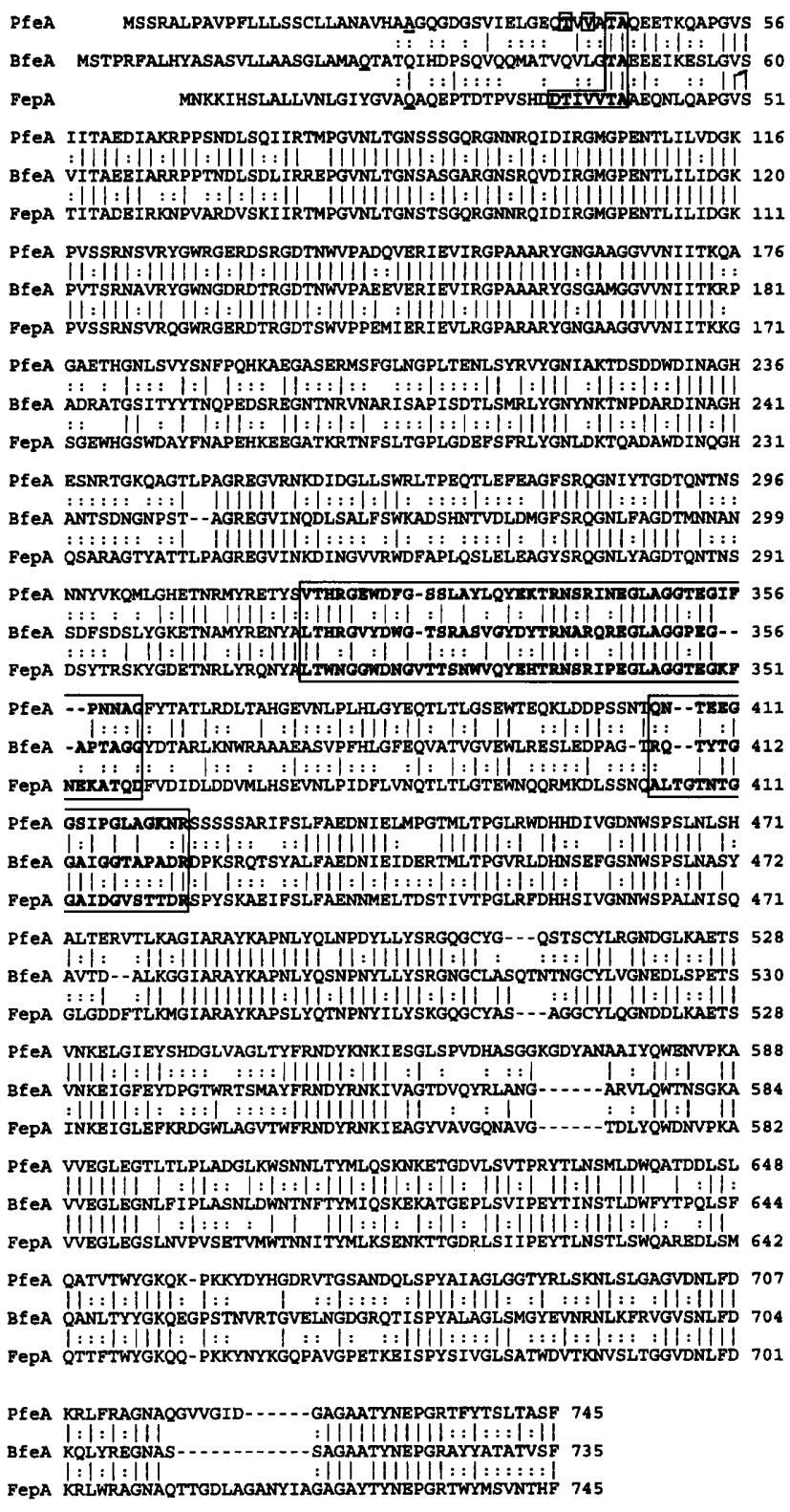

Fig. 3. Comparison of $B f e A$ with the enterobactin receptors FepA and PfeA of $E$. coli and $P$. aeruginosa, respectively. The comparisons were done with the FASTP algorithm of Pearson \& Lipman (1988). Sequences corresponding to the TonB box of $E$. coli receptors (residues 34-40 of FepA) and putative ligandbinding sites of FepA are boxed (residues 323-358 and 404-422) (Murphy \& Klebba, 1990). The predicted first residues of the mature proteins are underlined.

cated in ligand binding (Murphy et al., 1990). The 'blue halo effect' (Giladi et al., 1993) that we observed with strain KS330(pPK5) was also consistent with previous studies in which FepA-PhoA fusion proteins containing 227-710 residues of the mature FepA $\mathrm{N}$-terminus were localized to the outer membrane (Murphy \& Klebba, 1989).

Potential -35 and -10 hexamer sequences homologous to the consensus sequence recognized by the major form
1

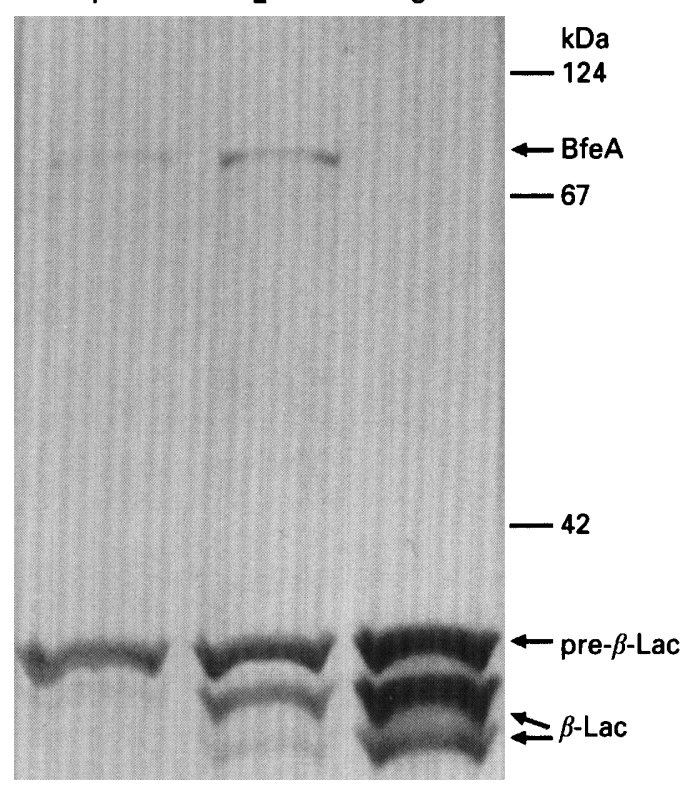

Fig. 4. Identification of the $b f e A$ gene product. $E$. coli $B L 21(\lambda D E 3)$ harbouring the vector $(\mathrm{pCl}$, lane 3$)$ or bfeA cloned into $\mathrm{pCl}$ (pCl7, lanes 1 and 2) untreated (lanes 2 and 3 ) or treated with sodium azide (lane 1) were labelled with $\left.{ }^{35} \mathrm{~S}\right]$ methionine for $5 \mathrm{~min}$ as previously described (Tabor \& Richardson, 1985; Baumler \& Hantke, 1992). Bands were detected by autoradiography. $\beta$-LaC, $\beta$-lactamase. Results are representative of repeated experiments using several independent transformants.

of E. coli RNA polymerase lie at positions 285-323 (Fig. 2) (Hawley \& McClure, 1983). These putative -35 and -10 sequences are both overlapped by sequences similar to Fur-binding sites. The sequence from 318 to 336 overlapping the -10 hexamer is identical to the consensus Fur-binding site in 11 of 19 positions (Calderwood \& Mekalanos, 1987) and identical to the Fur-binding site in the E. coli fbu $A$ promoter in 14 of 19 positions (sources of the references for the consensus and $f b u A$ sequences given in Braun et al., 1990).

\section{Identification of the bfeA gene product}

Plasmid pCI7, containing the bfe $A$ gene on a $2.3 \mathrm{~kb}$ $X m n \mathrm{I}-\mathrm{NcoI}$ fragment (position 333-2620; Fig. 2) under the control of the phage T7 promoter, was used to selectively label the $b f e A$ gene product with $\left[{ }^{35} \mathrm{~S}\right]$ methionine (Fig. 4). The bla gene encoding $\beta$ lactamase is in the same orientation as bfe $A$ on this plasmid, situated downstream of $b f e A$, and therefore is also under T7 promoter control. Upon IPTG induction of T7 RNA polymerase a protein of approximately $78 \mathrm{kDa}$ was radiolabelled in cells containing pCI7; this probably corresponds to the mature form of BfeA (Fig. 4, lanes 1 and 2). To prevent cleavage of the $\mathrm{BfeA}$ precursor, sodium azide, an inhibitor of SecA-mediated protein export (Fortin et al., 1990; Oliver et al., 1990) was added to half of the sample before labelling. While the precursor of the plasmid-encoded exported protein $\beta$-lactamase was 


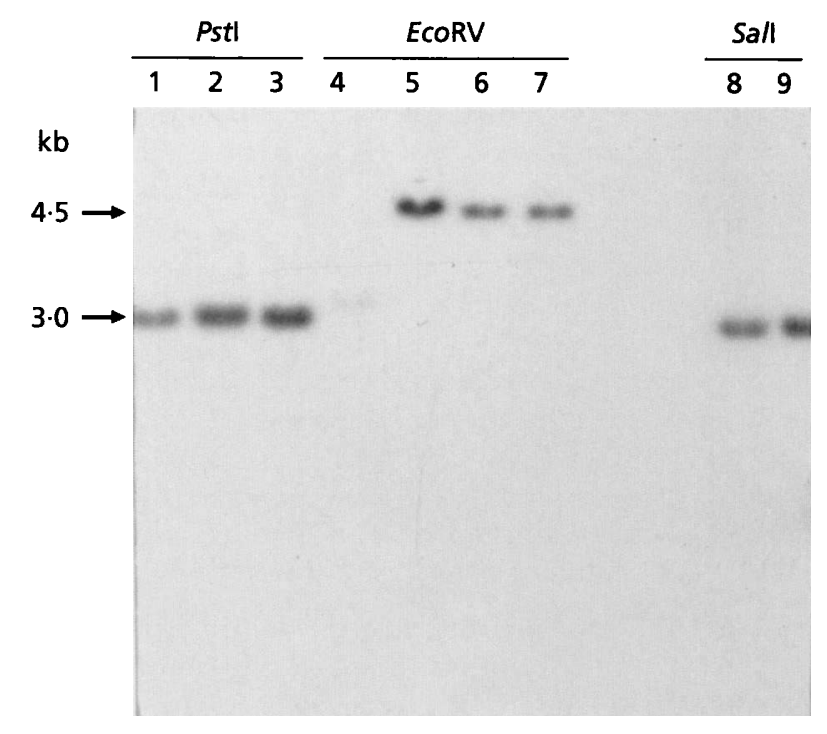

Fig. 5. Conservation of the bfeA gene and flanking region in Bordetella species. Chromosomal DNAs from B. pertussis (lanes 1, 5 and 8), B. parapertussis (lanes 2, 6 and 9), B. bronchiseptica (lanes 3 and 7), and B. avium (lane 4) were subjected to highstringency Southern analysis. The $736 \mathrm{bp}$ Sall-Stul bfeA structural gene fragment (bases 717-1451 in Fig. 2) was used as the probe.

enriched by azide treatment, a band corresponding to the $\mathrm{BfeA}$ precursor was not evident and the band putatively corresponding to the mature $\mathrm{BfeA}$ protein was significantly reduced compared to the untreated sample (Fig. 4; compare lanes 1 and 2). The reduction of mature $\mathrm{BfeA}$ in azide-treated cells would be consistent with the expected inhibition of SecA-mediated protein transport. It is possible that the accumulation of $\mathrm{Bfe} A$ precursor resulting from azide treatment was not be observed due to degradation in the cytoplasm.

We were unable to detect the $\mathrm{BfeA}$ protein in stained $7 \cdot 5-12 \%$ gels after SDS-PAGE of outer membrane protein extracts of $B$. pertussis or B. bronchiseptica (with isogenic bfe $A$ mutants for comparison). This may have been due to the relatively low abundance of $\mathrm{BfeA}$ causing it to be obscured by other outer membrane proteins of the same mobility.

\section{Conservation of the bfeA gene among Bordetella species}

As seen in Fig. 5, bfe $A$ and flanking regions appear to be conserved among Bordetella species. The region is highly conserved between $B$. pertussis, $B$. broncbiseptica and $B$. parapertussis, since DNA from each of these three species gave restriction fragments indistinguishable in size that hybridized strongly to a $b f e A$ structural gene fragment probe. This result was seen with three different restriction digests (Fig. 5) (results of SalI for B. bronchiseptica not shown). EcoRV digests of $B$. avium DNA produced a single, less strongly hybridizing fragment of a different
Table 3. Growth zones of B. bronchiseptica strains on L-

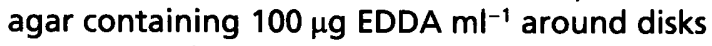
impregnated with enterobactin extract or enterobactinproducing $E$. coli strains

The diameters of growth zones were measured in mm after $24 \mathrm{~h}$ at $37^{\circ} \mathrm{C}$. To maintain chromosomal insertions, antibiotic selection was used as needed and E. coli strains were transformed with appropriate resistance vectors. The results are the mean for at least five separate experiments; the standard deviation in each case was less than $4 \mathrm{~mm}$.

\begin{tabular}{|c|c|c|c|c|}
\hline \multirow{2}{*}{$\begin{array}{l}\text { B. bronchiseptica } \\
\text { strain* }\end{array}$} & \multicolumn{3}{|c|}{ E. coli strain $\dagger$} & \multirow{2}{*}{$\begin{array}{c}\text { Enterobactin } \\
\text { extract }\end{array}$} \\
\hline & MC410 & MT91 & H306 & \\
\hline 19385 (wild-type) & 10 & 21 & 15 & 30 \\
\hline $\begin{array}{l}19386 \\
(=19385 \Omega \mathrm{pPK} 5)\end{array}$ & 11 & 20 & 14 & 32 \\
\hline $\begin{array}{l}19389 \\
(=19385 \Omega \mathrm{pVK} 11) \dagger\end{array}$ & 10 & 20 & 13 & 30 \\
\hline $\begin{array}{l}19388 \\
(=19385 \Omega \mathrm{pGN} 11) \dagger\end{array}$ & 11 & 19 & 14 & 32 \\
\hline $\begin{array}{l}19387 \\
(=19385 \Omega \mathrm{pKS} 3)\end{array}$ & 0 & 0 & 0 & 0 \\
\hline 19387(p415B1) $\ddagger$ & 12 & 21 & 16 & 29 \\
\hline 19387(pRK415) & 0 & 0 & 0 & 0 \\
\hline
\end{tabular}

* The symbol $\Omega$ indicates Campbell-type integration of the indicated plasmid containing the chromosomal restriction fragments depicted in Fig. 7.

† All these strains are aro $B^{+}$. All the $B$. bronchiseptica strains listed were also tested with the aroB E. coli strains H5058, H1443 and H1876; no growth was obtained with any of these strain combinations.

$\ddagger$ An identical plasmid, except containing the opposite orientation of the chromosomal fragment, was used with identical results.

size from the respective hybridizing EcoRV fragments generated from the other three Bordetella species (Fig. 5, lane 4).

\section{Utilization of enterobactin by B. pertussis and B. bronchiseptica}

To determine if Bordetella species were capable of utilizing ferric enterobactin, a disk method was employed as described in Methods. Only aro $B^{+}$enterobactin-producing $E$. coli strains were capable of stimulating growth of $B$. bronchiseptica on SS-Fe containing $45 \mu \mathrm{g}$ EDDA ml ${ }^{-1}$ or L-agar plates containing $100 \mu \mathrm{g} \mathrm{EDDA} \mathrm{ml}{ }^{-1}$ (Table 3). It was not possible to demonstrate stimulation of $B$. pertussis growth in this manner since evidently the $E$. coli strains secreted substance(s) inhibitory or lytic to B. pertussis. This was shown by control experiments in the absence of EDDA, which resulted in wide zones devoid of growth around the $E$. coli-containing disks (data not shown). Enterobactin-enhanced growth by $B$. pertussis and $B$. bronchiseptica was apparent in SS-Fe broth cultures 


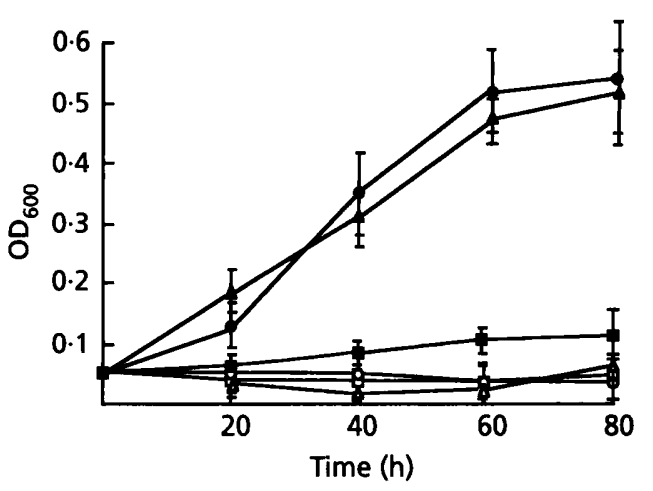

Fig. 6. BfeA-dependent enterobactin-enhanced growth of $B$. pertussis. The bfeA mutant strain 84 (squares), strain 84(p415B1) (triangles), and the parental wild-type strain 82 (circles) were grown to mid-exponential phase in iron-replete medium, washed, and inoculated into SS-Fe containing $25 \mu \mathrm{g}$ EDDA $\mathrm{ml}^{-1}$ (open symbols) or the same medium additionally containing $5 \mu \mathrm{M}$ enterobactin (filled symbols). Strains 84 and 84(p415B 1) cultures also contained $15 \mu \mathrm{g}$ kanamycin $\mathrm{ml}^{-1}$. These results show the mean and standard deviation of three identical experiments.

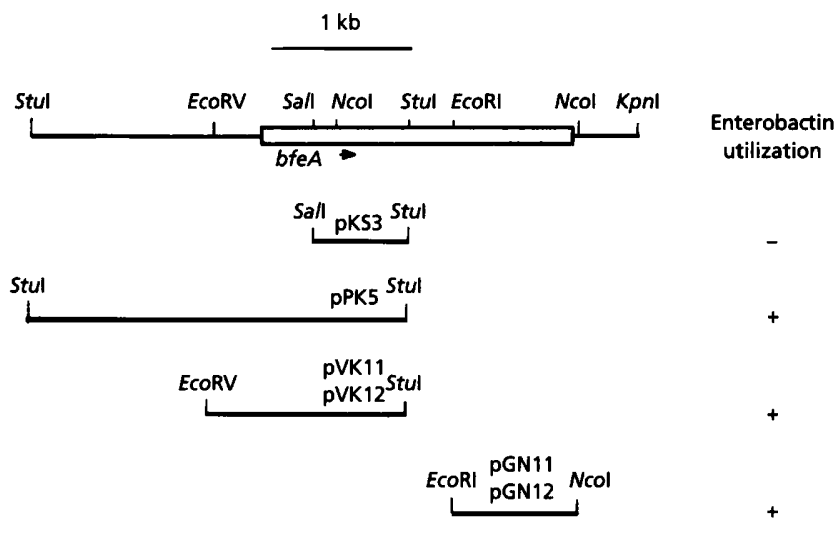

Fig. 7. Integrational analysis of the $b f e A$ gene region. The region from 38 bp upstream of the EcoRV site to approximately $50 \mathrm{bp}$ upstream of the $K p n I$ site represents the sequenced DNA shown in Fig. 2. Plasmid pKS3 is a derivative of plasmid pUK19 while pVK11, pVK12, pGN11 and pGN12 are pSS1129 derivatives. Plasmid pPK5 is a pPK3 derivative (see Methods). The resultant plasmids were integrated into the chromosome by conjugation (pVK11, pVK12, pGN11 and pGN12) or by transformation (pPK5 and pKS3) of wild-type $B$. pertussis and $B$. bronchiseptica. Ability to utilize enterobactin was assessed.

containing EDDA (Fig. 6, shown for B. pertussis only). Similar results were obtained by inoculating $B$. pertussis strain 82 onto minimal agar medium containing EDDA and $5 \mu \mathrm{M}$ enterobactin (not shown).

\section{Enterobactin utilization is bfeA-dependent in $B$. pertussis and $B$. bronchiseptica}

To facilitate the insertional inactivation of $b f e A$ in $B$. pertussis and $B$. bronchiseptica, a fragment of the $B$. pertussis bfe $A$ structural gene was subcloned into the vector pUK19 (Driks et al., 1994) to make pKS3 (Fig. 7). pKS3 cannot replicate in Bordetella species but contains a kanamycin resistance gene that is selectable in these hosts. As predicted, integration of $\mathrm{pKS} 3$ into the chromosomes of $B$. bronchiseptica and $B$. pertussis resulted in each containing a $b f e A$ allele truncated at the $S t u I$ site (identical hybridization data for each strain not shown) and coincided with drastically reduced enterobactin utilization in strains 84 (Fig. 6) and 19387 (Table 3). The wild-type $B$. pertussis and $B$. bronchiseptica strains were unable to grow on solid medium containing EDDA, but unlike the $b f e A$ mutants 84 and 19387, the addition of enterobactin stimulated their growth (data not shown). aroB ${ }^{+}$strains of $E$. coli capable of enterobactin synthesis stimulated the growth of B. bronchiseptica on L-agar containing $100 \mu \mathrm{g}$ EDDA ml ${ }^{-1}$, while aroB strains did not allow growth.

Previous work has demonstrated the ability of $B$. pertussis and $B$. bronchiseptica to utilize human holo-lactoferrin and holo-transferrin (Agiato \& Dyer, 1992; Agiato-Foster \& Dyer, 1993; Menozzi et al., 1991). Insertional inactivation of $b f e A$ in $B$. pertussis and B. bronchiseptica by Campbell insertion of pKS3 had no effect on the ability of these strains to utilize human holo-transferrin in similar experiments (data not shown). This observation was expected, since catechol siderophores are not detectable in ironstarved Bordetella cultures (Agiato \& Dyer, 1992; Armstrong \& Clements, 1993; Gorringe et al., 1990). These $b f e A$ mutants were also identical to the wild-type parental strains in their growth rates and cell density accumulation in SS $+\mathrm{Fe}$, SS-Fe without added iron, and in the presence of low EDDA and DP concentrations. These results indicated that the normal growth of these strains and their use of endogenous siderophores was not affected (data not shown).

\section{Functional boundaries of $b f e A$}

The $3 \mathrm{~kb} E c o \mathrm{RV}-K p n \mathrm{I}$ fragment from an EcoRV deletion derivative of $\mathrm{pKP} 1$ was cloned as a $B a m \mathrm{HI}$ fragment in both orientations into the replicative plasmid pRK415, resulting in plasmids $\mathrm{p} 415 \mathrm{~B} 1$ and $\mathrm{p} 415 \mathrm{~B} 2$. These plasmids, which contain the $b f e A$ gene and 370 bp of upstream sequence, were introduced by conjugation into the $b f e A$ mutant strains 84 and 19387. Enterobactin utilization experiments indicated that both $\mathrm{p} 415 \mathrm{~B} 1$ and $\mathrm{p} 415 \mathrm{~B} 2$ fully complemented these $b f e A$ mutants (Table 3, Fig. 6).

Chromosomal integration of the pSS1129 derivatives pVK11 and pVK12, which contain opposite orientations of a fragment consisting of about $1 \mathrm{~kb}$ of $5^{\prime}$ bfe $A$ sequence preceded by 370 bp of upstream DNA (Fig. 7), had no discernible effect on enterobactin utilization in either $B$. pertussis (not shown) or B. bronchiseptica (Table 3). Integration of $\mathrm{pVK} 11$ and $\mathrm{pVK} 12$ by a single crossover event into the chromosome resulted in one complete chromosomal copy of the $b f e A$ structural gene with 370 bp of upstream chromosomal sequence (hybridization data not shown). Integration of pGN11 and pGN12 (Fig. 7), containing a sequence (subcloned into the pSS1129 EcoRI site in opposite orientations) extending from the EcoRI site within $b f e A$ to the $N c o$ I site that barely encompasses the $3^{\prime}$ end of $b f e A$, had no effect on 
enterobactin utilization in B. pertussis (data not shown) or $B$. bronchiseptica (Table 3). These results, together with the ability of plasmids p415B1 and p415B2 to fully complement the $b f e A$ mutants (Table 3, Fig. 6), indicated that the expression of $b f e A$ does not require further upstream sequence. These results also suggested that the defective phenotype conferred by Campbell insertion of pKS3 is not likely to be due to polarity effects of the insertion on downstream genes.

\section{The bfeA gene on a multicopy plasmid does not complement $E$. coli fepA mutants}

Plasmid pKP1 was transformed into the three E. colifep $A$ mutants described in Table 2, but the capability to utilize enterobactin was not conferred upon these strains. Strain MT912(pKP1) was grown in L-broth containing different inhibitory concentrations $\left(50-450 \mu \mathrm{g} \mathrm{ml}^{-1}\right)$ of EDDA and actually grew somewhat more slowly than strain MT912(pUK19) under the same conditions (data not shown). Similarly, the aroB strains H5058(pKP1), H1876(pKP1) and H1443(pKP1) were spread onto kanamycin L-agar plates containing different inhibitory concentrations $(50-200 \mu \mathrm{M})$ of DP and tested for the ability to grow around disks impregnated with H306(pUK19), MT912(pUK19), or enterobactin extract. Only the control strain H1443(pKP1), which, unlike the other aroB strains, is fep $A^{+}$, displayed a zone of growth around the disks showing enterobactin utilization (not shown). The $b f e A-p h o A$ fusion was well expressed from pPK5 in strain KS330(pPK5) (Table 4). Since pPK5 contains the same region upstream of $b f e A$ that is upstream of $b f e A$ in $\mathrm{pKP} 1$, it is likely that $b f e A$ was expressed in the $f e p A$ mutants tested. Sequence analysis of the putative $b f e A$ promoter region and structural gene sequences shared between pPK5 and pKP1 showed no differences. Additionally, the $X m n \mathrm{I}-\mathrm{NcoI}$ fragment subcloned from pKP1 into a T7 expression vector was demonstrated to encode a protein of the predicted size of BfeA (Fig. 4).

\section{Expression of the bfeA gene}

The presence of potential Fur-binding sites overlapping the putative $b f e A$ promoter and the observation that $b f e A$ expression is iron-regulated in E. coli (Table 4) suggests that expression of $b f e A$ is repressed by Fur, with iron as its co-repressor. The $b f e A$ gene was cloned as a consequence of its iron-regulated expression in E. coli KS330(pPK5). Higher AP activity resulted from expression of the bfe $A-p h o A$ translational fusion in the presence of the iron chelator DP than during growth under iron-sufficient conditions (Table 4). The relatively high level of AP activity in strain KS330(pKP5) during growth with nonlimiting iron concentrations was possibly caused by inefficient regulation of $b f e A$ expression. This could be due to low-affinity binding to the promoter region by the $E$. coli Fur and/or a multi-copy effect, since multiple copies of Fur-regulated genes are not as tightly regulated as when they are in a single copy (Stojiljkovic et al., 1994). In contrast, the same $b f e A-p b o A$ translational fusion present as a single chromosomal copy in B. pertussis and $B$. bronchiseptica was tightly iron-regulated (Table 4).

AP activity was induced equally in B. bronchiseptica 19386 by growth in SS-Fe or SS-Fe $+50 \mu \mathrm{M}$ DP (data not shown), indicating that the iron levels in SS-Fe were low enough for complete derepression of $b f e A$. This observation correlated with a slightly slower growth rate and decreased final cell density of $B$. pertussis and $B$. bronchiseptica strains in SS-Fe compared to growth in $\mathrm{SS}+\mathrm{Fe}$ (data not shown) and the apparently complete deregulation of iron-regulated proteins in $\mathrm{SS}-\mathrm{Fe}$ in $B$. bronchiseptica and $B$. pertussis seen by SDS-PAGE (data not shown). In contrast to $p f e A$ expression in $P$. aeruginosa, which requires the presence of enterobactin in addition to iron limitation for its induction (Poole $e t$ al., 1990; Dean \& Poole, 1993a, b), bfe A expression was induced solely by iron limitation in both Bordetella species (Table 4). As described previously for iron-mediated repression of siderophore production in B. pertussis (Agiato \& Dyer, 1992), the presence of $200 \mu \mathrm{g} \mathrm{ml} \mathrm{m}^{-1}$ of human holotransferrin in addition to growth-inhibiting levels of EDDA in SS-Fe restored growth and eliminated bfe $A$ expression in B. pertussis and in B. bronchiseptica (data not shown).

E. coli $\mathrm{KS} 330$ (pPK3) showed the same levels of AP activity as KS330(pPK5) (Table 4; pPK3 contains the same $b f e A-p h o A$ gene fusion as does pPK5 except that upstream chromosomal sequence has been deleted to the $E c o R V$ site upstream of $b f e A$ : Fig. 7) in both iron-limiting and iron-replete conditions. These results indicated that it is likely that the sequence(s) responsible for iron-regulated $b f e A$ expression lies between the $b f e A$ translational start and the upstream EcoR $V$ site. This contention was reinforced by the wild-type phenotypes of Bordetella strains 86 (not shown), 19389, 84(p415B1,2) and 19387(p415B1,2) (Table 3, Fig. 7). In these strains the bfe $A$ gene is preceded by chromosomal DNA only up to the EcoRV site 370 bp upstream, and three potential Furbinding sites lie within this upstream sequence (Fig. 2).

\section{DISCUSSION}

The ability of Gram-negative bacteria such as $P$. aeruginosa, E. coli and Haemophilus species to utilize heterologous siderophores for iron acquisition has been established (Poole et al., 1990; Hantke \& Braun, 1975; Williams et al., 1990). In this work we describe the cloning, nucleotide sequence, and phenotypic analysis of a gene highly homologous to the enterobactin receptor genes of $P$. aeruginosa and $E$. coli that is required for exogenous enterobactin utilization by $B$. pertussis and B. bronchiseptica.

As discussed earlier (Dean \& Poole, 1993a), two regions of FepA have been implicated in ligand binding by the use of monoclonal antibodies to block binding of ferric enterobactin and colicins to FepA (Murphy et al., 1990). These regions are indicated in Fig. 3 as residues 311-358 and 404-422 of FepA. As with PfeA, the central portion of $\mathrm{BfeA}$ corresponding to residues $311-358$ of FepA is most similar to this region of FepA, with much less similarity at each end (18 identities to FepA over residues 
Table 4. bfeA-phoA expression experiments

\begin{tabular}{|lcc|}
\hline Strain & \multicolumn{2}{c|}{$\begin{array}{c}\text { AP units } \\
\text { (mean } \pm \text { SD, } \boldsymbol{n}=3 \text { ) }\end{array}$} \\
\cline { 2 - 3 } & $+\mathbf{F e}$ & $-\mathbf{F e}$ \\
\hline E. coli KS330(pPK5)* & $75 \pm 20$ & $300 \pm 65$ \\
E. coli KS330(pPK3)* & $97 \pm 25$ & $335 \pm 53$ \\
B. broncbiseptica $19386 \dagger$ & $5 \pm 3$ & $125 \pm 24$ \\
B. pertussis $83 \dagger$ & $2 \pm 2$ & $15 \pm 4$ \\
\hline
\end{tabular}

* Mid-exponential-phase cells were incubated for $3 \mathrm{~h}$ in L-broth ( $+\mathrm{Fe}$ ) or in L-broth containing $200 \mu \mathrm{M} \mathrm{DP}(-\mathrm{Fe})$.

$\dagger$ Cells were grown to late exponential phase in $\mathrm{SS}+\mathrm{Fe}$, containing $50 \mu \mathrm{M} \mathrm{FeCl}_{3}(+\mathrm{Fe})$, or in $\mathrm{SS}-\mathrm{Fe}$, lacking added iron supplement $(-\mathrm{Fe})$.

330-358 with PfeA and 13 identities to FepA over this region with $\mathrm{Bfe} A$ ). The region of $\mathrm{Bfe} A$ corresponding to residues 404-422 of FepA also has significant homology to FepA, with 9 identities and 6 conservative substitutions over 19 residues. The regions of BfeA similar to putative ligand-binding sites of FepA, the high homology of BfeA over its entire length with the FepA and PfeA enterobactin receptors, and the drastically decreased ability of $B$. pertussis and $B$. bronchiseptica bfe $A$ mutants to utilize enterobactin implicate $\mathrm{BfeA}$ as a ferric enterobactin receptor.

The BfeA protein, unlike PfeA (Dean \& Poole, 1993a), apparently does not function properly in E. coli, possibly due to its inability to interact with TonB or other proteins involved in transport and intracellular release of iron from ferric enterobactin. A region sharing some similarity with the seven-residue 'Ton B box' is evident in BfeA, but only two of seven residues are identical to FepA while four of the seven are identical between PfeA and FepA (Fig. 3, residues 34-40 of FepA). The two most conserved residues in the TonB box of the large group of TonBdependent outer membrane receptors are the threonine and valine residues corresponding to positions of 35 and 37 of FepA (Baumler \& Hantke, 1992) (Fig. 3), which are absent in BfeA. Further work is required to examine the conservation between ton $B$ and the other genes required for ferric enterobactin utilization in $E$. coli with their counterparts in Bordetella.

The iron-regulated expression of $b f e A$ (Table 4) and the putative Fur-binding sites preceding $b f e A$ (Fig. 2) suggest that its expression may be controlled solely by the transcriptional regulator Fur complexed to iron. In $B$. pertussis and $B$. bronchiseptica expression of $b f e A$ was stimulated by iron-limitation alone, while the addition of enterobactin during iron-limited growth had no effect on $b f e A$ expression (data not shown). This differs from the expression of the $P$. aeruginosa $p f e A$ gene, which requires the presence of enterobactin as well as low iron availability for its induction (Poole et al., 1990). Immediately upstream of the $p f e A$ gene lie the $p f e S$ and $p f e R$ genes, which constitute a 'two-component' transcriptional regulator that mediates enterobactin-dependent transcription of pfe $A$ (Dean \& Poole, 1993b). Limited sequence analysis of a total of about $700 \mathrm{bp}$ of the $1.4 \mathrm{~kb}$ of DNA upstream of $b f e A$ in plasmid pPK5 revealed no homology to $p f e \mathrm{R}$ and $p f e S$ (data not shown).

It should be noted here that $b f e A$ expression studies and functional analysis of $b f e A$ were much more straightforward in B. bronchiseptica than in B. pertussis. Both of these organisms can reach $\mathrm{OD}_{600}$ values of at least 2.5 in SS-Fe, although $B$. pertussis has a much slower growth rate. Wild-type $B$. pertussis would only reach a maximal $\mathrm{OD}_{600}$ of approximately 0.6 in SS-Fe containing $25 \mu \mathrm{M}$ EDDA plus $5 \mu \mathrm{M}$ enterobactin after more than $2 \mathrm{~d}$ at $37^{\circ} \mathrm{C}$ (Fig. 6), while B. broncbiseptica could reach an $\mathrm{OD}_{600}$ of greater than 2.0 in SS-Fe containing $45 \mu \mathrm{M}$ EDDA plus $5 \mu \mathrm{M}$ enterobactin within $24 \mathrm{~h}$ (data not shown). Similarly, the iron-regulated expression of $b f e A$ was much more evident in B. bronchiseptica than in B. pertussis (Table 4).

The conservation of the $b f e A$ region among $B$. pertussis, $B$. parapertussis and B. bronchiseptica (Fig. 5) is consistent with them being considered subspecies (Kloos et al., 1981). Similar studies concerning the more distant relative $B$. avium should prove interesting. DNA hybridization results indicate that $B$. avium has a DNA sequence homologous to the $b f e A$ gene, but the homology is less than that observed between $b f e A$ and the putative $b f e A$ genes from B. parapertussis and B. bronchiseptica (Fig. 5).

Enterobactin-producing members of the family Enterobacteriaceae are occasionally encountered in clinical respiratory tract specimens, where they may be involved in transient colonization or infectious processes, including superinfection after infection by common respiratory pathogens such as $B$. pertussis. Haemophilus parainfluenzae and Haemophilus paraphrophilus are common commensals of the human upper respiratory tract that have been demonstrated to utilize exogenous enterobactin in vitro. These Haemophilus species are likely to internalize ferric enterobactin via a FepA homologue since they have a DNA sequence highly homologous to $f e p A$, and $H$. parainfuenzae expresses an iron-repressible outer membrane protein that reacts with anti-FepA serum (Williams et al., 1990). It seems likely that the expression of a functional enterobactin receptor in Bordetella, Haemophilus and Pseudomonas species may have served an evolutionary advantage. Further work will be necessary to determine the significance of the expression of these enterobactin receptors in vivo.

\section{ACKNOWLEDGEMENTS}

We are grateful to Tim Brickman, Charles Dean, Klaus Hantke, Terri Kenney, Scott Stibitz and Kathryn Strauch for strains, plasmids, and advice. We thank Shambavi Subbarao for critically reading this manuscript.

\section{REFERENCES}

Agiato, L.-A. \& Dyer, D. W. (1992). Siderophore production and membrane alterations by Bordetella pertussis in reponse to iron starvation. Infect Immun 60, 117-123. 
Agiato-Foster, L.-A. \& Dyer, D. W. (1993). A siderophore production mutant of Bordetella broncbiseptica cannot use lactoferrin as an iron source. Infect Immun 61, 2698-2702.

Armstrong, S. K. \& Clements, M. O. (1993). Isolation and characterization of Bordetella bronchiseptica mutants deficient in siderophore activity. J Bacteriol 175, 1144-1152.

Baumler, A. J. \& Hantke, K. (1992). Ferrioxamine uptake in Yersinia enterocolitica: characterization of the receptor protein FoxA. Mol Microbiol 6, 1309-1321.

Beall, B. \& Sanden, G. N. (1995). Cloning and initial characterization of the Bordetella pertussis fur gene. Curr Microbiol 30, 1-4.

Braun, V. \& Hantke, K. (1991). Genetics of bacterial iron transport. In Handbook of Microbial Iron Chelates, pp. 107-138. Edited by G. Winkelmann. Boca Raton, FL: CRC Press.

Braun, V., Schaffer, S., Hantke, K. \& Troger, W. (1990). Regulation of gene expression by iron. In The Molecular Basis of Bacterial Metabolism, pp. 164-179. Edited by G. Hauska \& R. Thauer. New York: Springer.

Brickman, E. \& Beckwith, J. (1975). Analysis of the regulation of Escherichia coli alkaline phosphatase using deletions and 80 transducing phages. $J$ Mol Biol 96, 307-316.

Brickman, T. J. \& Armstrong, S. K. (1995). Bordetella pertussis fur gene restores iron repressibility of siderophore and protein expression to deregulated Bordetella bronchiseptica mutants. J Bacteriol 177, 268-270.

Bron, S. (1990). Plasmids. In Molecular Biological Methods for Bacillus, pp.75-174. Edited by C. R. Harwood \& S. M. Cutting. New York: Wiley.

Calderwood, S. B. \& Mekalanos, J. J. (1987). Iron regulation of Shiga-like toxin expression in Escherichia coli is mediated by the fur locus. J Bacteriol 169, 4759-4764.

Dean, C. R. \& Poole, K. (1993a). Cloning and characterization of the ferric enterobactin receptor (PfeaA) of Pseudomonas aeruginosa. $J$ Bacteriol 175, 317--324.

Dean, C. R. \& Poole, K. (1993b). Expression of the ferric enterobactin receptor (PfeA) of Pseudomonas aeruginosa : involvement of a two-component regulatory system. Mol Microbiol 8, 1095-1103.

Driks, A., Roels, S., Beall, B., Moran, C. P. \& Losick, R. (1994). Subcellular localization of proteins involved in the assembly of the spore coat of Bacillus subtilis. Genes \& Dev 8, 234-244.

Fortin, Y., Phoenix, P. \& Drapeau, G. (1990). Mutations conferring resistance to azide in Escherichia coli occur primarily in the $\sec A$ gene. J Bacteriol 172, 6607-6610.

Giladi, M., Champion, C. I., Haake, D. A., Blanco, D. R., Miller, J. F., Miller, J. N. \& Lovett, M. E. (1993). Use of the 'blue halo' assay in the identification of genes with cleavable signal peptides: cloning of a Borrelia burgdorferi plasmid gene with a signal peptide. J Bacteriol 175, 4129-4136.

Gorringe, A. R., Woods, G. \& Robinson, A. (1990). Growth and siderophore production by Bordetella pertussis under iron-restricted conditions. FEMS Microbiol Lett 66, 101-106.

Hantke, K. \& Braun, V. (1975). Membrane receptor dependent iron transport in Escherichia coli. FEBS Lett 49, 301-305.

Hawley, D. K. \& McClure, W. R. (1983). Compilation and analysis of Eschericbia coli promoter DNA sequences. Nucleic Acids Res 11, $2237-2255$

Heinrichs, D. E., Young, L. \& Poole, K. (1991). Pyochelin-mediated iron transport in Pseudomonas aeruginosa: involvement of a highmolecular mass outer membrane protein. Infect Immun 59, 3680-3684

Keen, N. T., Kobayashi, D. \& Trollinger, D. (1988). Improved broad-host-range plasmids for DNA cloning in Gram-negative bacteria. Gene 70, 191-197.

Kloos, W. E., Mohapatra, W. J., Dobrogosg, W. J., Ezzell, J. W. \& Manclark, C. R. (1981). Deoxyribonucleotide sequence relationships among Bordetella species. Int J Syst Bacteriol 31, 173-176.

von Koenig, C. H. W., Tacken, A. \& Finger, H. (1988). Use of supplemented Stainer-Scholte broth for the isolation of Bordetella pertussis from clinical material. J Clin Microbiol 26, 2558-2560.

Langman, L., Young, I. G., Frost, G. E., Rosenburg, H. \& Gibson, F. (1972). Enterochelin system of iron transport in Escherichia coli: mutations affecting ferric-enterochelin esterase. J Bacteriol 112, 1142-1149.

Lundrigan, M. D. \& Kadner, R. J. (1986). Nucleotide sequence of the gene for the ferrienterochelin receptor FepA in Escherichia coli: homology among outer membrane receptors that interact with TonB. J Biol Chem 261, 10797-10801.

Manoil, C. \& Beckwith, J. (1985). Tnpho $A$ : a transposon probe for protein export signals. Proc Natl Acad Sci US A 82, 8129-8133.

Menozzi, F. D., Gauntiez, C. \& Locht, C. (1991). Identification and purification of transferrin- and lactoferrin-binding proteins of Bordetella pertussis and Bordetella bronchiseptica. Infect Immun 59, 3982-3988.

Messing, J. (1983). New M13 vectors for cloning. Methods Enzymol 101, 20-77

Meyer, J. M., Hohnadel, D., Khan, A. \& Cornelius, P. (1990). Pyoverdin-facilitated iron uptake in Pseudomonas aeruginosa: immunological characterization of the ferripyoverdine receptor. Mol Microbiol 4, 1401-1405.

Moore, C. H., Foster, L.-A., Gerbig, D. G.,Jr, Dyer, D. W. \& Gibson, B. W. (1995). Identification of alcaligin as the siderophore produced by Bordetella pertussis and Bordetella bronchiseptica. J Bacteriol 177, 1116-1118.

Murphy, C. K. \& Klebba, P. E. (1989). Export of FepA:: PhoA fusions to the outer membrane of Escherichia coli K12. $J$ Bacteriol 171, 5894-5900.

Murphy, C. K., Kalve, K. I. \& Klebba, P. E. (1990). Surface topology of the Eschericbia coli K12 enterobactin receptor. Mol Microbiol 6, 1309-1321.

Neilands, J. B. (1981). In Development of Iron Chelators for Clinical Use, p. 13. Edited by A. E. Martell, W. F. Anderson \& D. G. Badman. New York: Elsevier/North-Holland.

O'Brien, I. G. \& Gibson, F. (1970). The structure of enterochelin and related 2,3-dihydroxy- $N$-benzoylserine conjugates from Escherichia coli. Biocbim Biophys Acta 251, 393-402.

Oliver, D. B., Cabelli, R. J., Dolan, K. M. \& Jarosick, G. P. (1990). Azide-resistant mutants of Escherichia coli alter the SecA protein, an azide-sensitive component of protein export machinery. Proc Natl Acad Sci US A 87, 8227-8231.

Pearson, W. R. \& Lipman, D. J. (1988). Improved tools for biological sequences comparison. Proc Natl Acad Sci USA 85, 2444-2448.

Perlman, D. \& Halvorson, H. O. (1983). A putative signal peptidase recognition site and sequence in eukaryotic and prokaryotic peptides. J Mol Biol 167, 391-409.

Pollack, J. R. \& Neilands, J. B. (1970). Enterobactin, an iron transport compound from Salmonella typhimurium. Biochem Biophys Res Commun 38, 989-992.

Poole, K., Young, L. \& Neshat, S. (1990). Enterobactin-mediated iron transport in Pseudomonas aeruginosa. J Bacteriol 172, 6991-6996. 
Redhead, K. \& Hill, T. (1991). Acquisition of iron from transferrin by Bordetella pertussis. FEMS Microbiol Lett 77, 303-308.

Redhead, K., Hill, T. \& Chart, H. (1987). Interaction of transferrin and lactoferrin with the outer membrane of Bordetella pertussis. J Gen Microbiol 133, 891-898.

Regan, J. \& Lowe, F. (1977). Enrichment medium for the isolation of Bordetella. J Clin Microbiol 6, 303-309.

Schneider, D. R. \& Parker, C. D. (1982). Effect of pyridines on phenotypic properties of Bordetella pertussis. Infect Immun 38, 548-553.

Stibitz, S. (1994). Use of conditionally counterselective suicide vectors for allelic exchange. Methods Enzymol 235, 458-465.

Stojiljkovic, I., Baumler, A. J. \& Hantke, K. (1994). Fur regulon in gram negative bacteria: identification and characterization of new iron-regulated Escherichia coli genes by a Fur titration assay. $\mathrm{J} \mathrm{Mol}$ Biol 236, 531-545.

Strauch, K. L. \& Beckwith, J. (1988). An Escherichia coli mutation preventing degradation of abnormal periplasmic proteins. Proc Natl Acad Sci US A 85, 1576-1580.

Strauch, K. I., Johnson, K. \& Beckwith, J. (1989). Characterization of $\operatorname{deg} P$, a gene required for proteolysis in the cell envelope and essential for growth of Escherichia coli at high temperature. $J$ Bacteriol 171, 2689-2696.

Struyve, M., Moons, M. \& Tommassen, J. (1991). Carboxy-terminal phenylalanine is essential for the correct assembly of a bacterial outer membrane protein. $J$ Mol Biol 218, 141-148.

Tabor, S. \& Richardson, C. C. (1985). A bacteriophage T7 RNA polymerase/promoter system for controlling exclusive expression of specific genes. Proc Natl Acad Sci US A 82, 1074-1078.

Wang, C. C. \& Newton, A. (1971). An additional step in the transport of iron defined by the tonB locus of Escherichia coli. J Biol Cbem 246, 2147-2151.

Wayne, R. R. \& Neilands, J. B. (1976). Relation of siderophore utilization to colicin receptor activity in mutants of E. coli K-12 resistant to colicins B, V, or Ia. Fed Proc 35, 1453.

Williams, P., Morton, D. J., Towner, K. J., Stevenson, P. \& Griffiths, E. (1990). Utilization of enterobactin and other exogenous iron sources by Haemophilus influenqae, $H$. parainfluenzae and $H$. parapbrophilus. J Gen Microbiol 136, 2343-2350.

Received 11 May 1995; revised 4 August 1995; accepted 29 August 1995. 